\title{
Cancer researchers say NHS reforms undermining trials
}

London. The British government has been warned that its attempts to reform the $\mathrm{Na}$ tional Health Service (NHS) by reducing the role of central government in the allocation of resources is seriously undermining clinical trials of new cancer treatments.

The latest in a series of warnings about the impact of the NHS reforms on biomedical research has come from the United Kingdom Coordinating Committee on Cancer Research (UKCCCR), a body representing the major organizations funding cancer research in the United Kingdom.

Its conclusions reinforce those of a report, commissioned by the government from a group headed by Anthony Culyer, professor of medical economics at the University of York, which are believed to confirm that Britain's biomedical research base is being seriously threatened by the reforms.

Although delivered to ministers in April, the Culyer report has not yet been published - partly, it is widely believed, because of the embarrassment its conclusions are likely to cause the government, as they run contrary to its efforts to establish an internal marketplace for all NHS expenditure (see Nature 369, 514; 1994).

John Smyth, professor of clinical oncology at the University of Edinburgh, and chairman of the UKCCCR, says his committee's main concern is that government attempts to reduce health service costs by increasing competition for funds are "against the cooperative spirit of research" needed to carry out large-scale clinical trials.

$\mathrm{He}$ also claims that the attempts to address shortcomings in research support by making additional money available to teaching hospitals under the so-called Service Increment for Teaching and Research (SIFTR) scheme have failed to address the problem adequately, as it is often difficult to tell what such funds are being used for. "SIFTR is not the answer," says Smyth.

A survey conducted by a working party set up by the committee has revealed that more than half of those conducting clinical trials of new cancer treatments say they are experiencing difficulty in sustaining their involvement in such research. Factors leading to reduced effort include a lack of time and of support staff, with many respondents saying that the time now spent in administrative and managerial committees means that less time is available for research.

In its report, published in last week's issue of the British Medical Journal, the working party says that "the financial imperative from a market-based NHS to avoid the 'unnecessary' expense in undertaking a [clinical] trial is the basis of real conflict".

The working group suggests that one remedy would be to "top-slice" funds allocated to local health authorities, and develop a mechanism for distributing these to support national clinical trials. It also calls for a "radical change" in the way in which SIFTR funds are handled, allowing for a greater proportion to be allocated to following patients involved in such trials.

The report's main conclusions have been endorsed by individual cancer research organizations, concerned that reduced funding for patient care is requiring them to carry an increasing share of the costs of carrying out trials of new drugs and therapies.

But the government has so far given little indication that it is prepared to acknowledge that its NHS reforms have created a major problem for research. John Bowis, parliamentary secretary at the Department of Health, said in a statement that he rejects the UKCCCR's view that changes in the NHS signal a reduction in the government's commitment to ensuring that world-class clinical research continues to thrive.

Bowis pointed out that the government has already set a goal of increasing NHS spending on research and development to 1.5 per cent of its total expenditure. But he pointed out that the decision to ask for recommendations for "improvements" from Culyer had reflected the government's acceptance that there is a need to look again at mechanisms intended to ensure that such research and development is being properly funded. He also promised that the Culyer report will be published "shortly".

Such statements have so far failed to reassure the government's critics. "Our main concern is that its current attitude is generating a growing apathy among clinical researchers, many of whom are now seeking research opportunities abroad," says Smyth.

Such fears have recently been reinforced by the decision of several leading biomedical researchers - including $\mathrm{Bob}$ Williamson, professor of biochemistry at $\mathrm{St}$ Mary's Hospital and a pioneer of cystic fibrosis treatment, and Lucio Luzzatto, former head of haematology at the Hammersmith Hospital, both in London - to leave the country.

In announcing his planned departure last month, Williamson said that one of the key factors leading to his decision had been the growing difficulties of obtaining adequate support for research under the new organization of the NHS. The issue is already being taken up by the opposition Labour Party, which claims that the government's commitment to the 'internal market' policies for the health service "is effectively pulling the plug on research and development".

David Dickson

\section{Conference trail can leave behind a good image}

London. Been to any good conferences lately? If not, then it may be time to make amends. A report published in the journal Social Studies of Science $(24,513-548$; 1994) shows how an individual's record of attendance at scientific meetings may be as good a way of assessing intellectual quality as an analysis of the impact of his or her scientific publications.

Thomas Söderqvist of Roskilde University in Denmark and Arthur $M$. Silverstein of Johns Hopkins University School of Medicine in Baltimore, Maryland, analysed the attendance of 4,806 delegates who took part in 88 immunology meetings between 1951 and 1972, a period during which immunology became established as a distinct discipline.

The majority of participants $(72$ per cent of the total) attended only one meeting during the 23-year period. But almost all of the 1.6 per cent (79) who went to ten or more meetings can be identified by

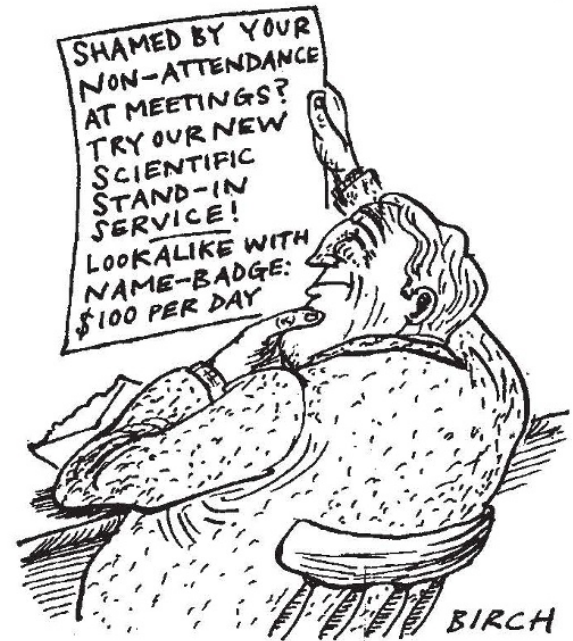

other criteria as leaders in the field.

Significantly, these criteria extend beyond simple citation records; some of the most frequent attendees had not made important discoveries themselves, but had been noted for (and made their contribution to the field through) their ability to spot talent in others.

Söderqvist and Silverstein's main goal was to spot trends in the structure and dynamics of an emerging field. But the study also seems likely to attract interest as a way of reinforcing other techniques for judging scientific quality.

The two researchers describe it as "astonishing" that analysis of the participation of scientists at meetings - a "pervasive and integral part of science" since the seventeenth century - has been generally neglected as a way of identifying research trends. 